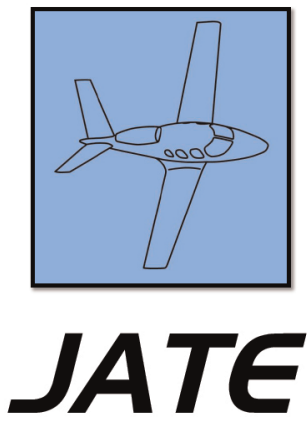

Journal of Aviation Technology and Engineering 3:2 (2014) 28-34

\title{
Decision to Use an Airframe Parachute in a Flight Training Environment
}

\author{
Scott R. Winter \\ Florida Institute of Technology \\ Richard O. Fanjoy, Chien-Tsung Lu, Thomas Q. Carney, and James P. Greenan \\ Purdue University
}

\begin{abstract}
The purpose of this study was to complete a qualitative analysis of the decision-making process used by pilots to determine whether or not to deploy an airframe parachute system. A sample of participants from the subject university's flight training program was selected to complete a scripted simulator flight in instrument flight conditions. During the flight, participants experienced an engine failure while enroute during IFR conditions. The script was examined and validated by an expert panel who determined use of the airframe parachute was the most appropriate outcome for the scenario. Interestingly, only 9 of the 21 participants responded as expected by the expert panel and deployed the parachute system; only three of the nine followed the correct deployment procedure as outlined in the Pilot's Operating Handbook. Analysis of a post-flight survey completed by participants provides insights into the decision-making process used by pilots and offers explanations on why or why not participants used the airframe parachute.
\end{abstract}

Keywords: ADM, airframe parachute, deployment decision making

\footnotetext{
About the Authors

Scott R. Winter, PhD, ATP, is an assistant professor of Aviation Science at the Florida Institute of Technology. Winter completed his doctorate degree from Purdue University in 2013, where his dissertation research focused on pilot decision making in irreversible emergencies. He presently conducts research in three foundational areas: pilots' transition and information processing in glass cockpit aircraft, training pilots in very light jet operations, and enhancement methods for pilot cognition and decision making.

Richard O. Fanjoy is associate department head in the Department of Aviation Technology at Purdue University. His principle teaching areas are air transportation, aircraft operations, cognitive modeling, principles of high-performance flight, research methods, and advanced aircraft flight systems/ instrumentation. He also manages the department's graduate program. Fanjoy has more than 30 years of experience as a pilot and flight examiner of large jet transport aircraft in both domestic and international flight operations.

Chien-tsung Lu is an associate professor in the Aviation Technology Department at Purdue University. He holds degrees from the University of Central Missouri and the University of Nebraska, and his research interests include aviation safety, airport security, and aviation policy making.

Thomas Q. Carney is a professor of Aviation Technology and former department head of the Department of Aviation Technology at Purdue University, where he has taught since 1972. He holds the Airline Transport Pilot certificate with multiengine, Mitsubishi Diamond, and Beechjet type ratings, and a Certified Flight Instructor certificate with airplane single- and multiengine and instrument airplane ratings. In addition to his flight background, Carney holds MS and PhD degrees in Atmospheric Science, and maintains a courtesy faculty appointment in the Department of Earth and Atmospheric Sciences at Purdue.

James P. Greenan is a professor and chair of Career and Technical Education within the Department of Curriculum and Instruction at Purdue University. His research interests include research methodology and program evaluation. He completed his PhD from the University of Minnesota in 1980. Correspondence concerning this article should be sent to scott.winter@mac.com.
} 


\section{Introduction}

When operating single-engine aircraft, pilots traditionally had one possible outcome after an engine-failure: a controlled glide to a forced landing (a landing that occurs off-site from an airport). Nonoptimum conditions may have added to the emergency complexity if the engine failure occurred over inhospitable terrain, during night hours or instrument flight conditions. With recent technological advancements, some aircraft are now equipped with an airframe parachute system that can be utilized in certain catastrophic emergencies. This airframe parachute, once deployed manually by the pilot, provides an alternative outcome to what otherwise may have been a very risky, dangerous or even deadly accident. Of interest in the present study is the decision-making process utilized by pilots operating an aircraft equipped with an airframe parachute system.

\section{Purpose of the Study}

The purpose of this study was to complete a qualitative analysis of the decision-making process used by pilots to determine whether or not to deploy an airframe parachute system. Participants completed a scripted flight scenario that resulted in an emergency engine failure in instrument flight conditions.

\section{Review of the Literature}

A comprehensive literature review was completed as part of this study. Major theories on decision making were analyzed to identify those which are most applicable in an aviation context. Further literature was examined to understand human factors issues appropriate to decision making within an aviation context, such as heuristics and biases.

\section{Naturalistic Decision Making within an Aviation Context}

There are a number of interesting theories that address decision making. However, the two that were isolated for study in this project were classical decision theory and naturalistic decision making (Lipshitz, Klein, Orasanu, \& Salas, 2001). Classical decision theory assumes that options are clearly known prior to making decisions and is an overarching term given to normative and prescriptive decision making (Beach \& Lipshitz, 1993). This theory assumes that there is a right and wrong choice that can be made, and this may not always be the case in aviation emergency situations (Lipshitz et al., 2001). The type of decision making that appears to be best suited and applicable within an aviation context is naturalistic decision making (NDM) (Klein, Orasanu, Calderwood, \& Zsambok, 1993). As defined by Lipshitz, et al. (2001), "NDM is an attempt to understand how people make decisions in realworld contexts that are meaningful and familiar to them" (p. 332). A key component to NDM is the recognition that decisions may have to be made without all the facts available, and this emphasis on real-world situations is very applicable to the aviation field. "In many high risk consequential environments, time for a decision is limited, information is incomplete, conditions change dynamically, and goals shift, rendering analytic decision making impractical, if not impossible" (Orasanu, 2010, p. 150). Craig (2000) further references the characteristics of naturalistic decisions as outlined by Orasanu and Connolly as "illstructured problems; uncertain dynamic environments; shifting, ill-defined or competing goals; action/feedback loops; time stress, high stakes; and multiple players" (pp. 22-23). Many, if not all, of these characteristics are applicable to aviation decisions in critical contexts.

Naturalistic decision-making theory will be applicable to the current study due to the dynamic and evolving environment related to aviation decision making. The subject university has utilized aircraft equipped with an airframe parachute system for approximately three years at the time this study was completed. Therefore, it was assumed that students and instructors will have adapted to this new safety feature, have been trained, and gained experience in having this system on-board. Since NDM is heavily influenced by previous experience, the researchers were particularily interested in how prior training would influence participants' decisions to utilize the airframe parachute.

\section{The Possible Influences of Heuristics and Biases on Aviation Decision Making}

Decision-making heuristics and biases were reviewed to determine their possible influence on aviation-related decision making. Heuristics are often associated with decision models and are defined as a "mental 'shortcut' involving psychological processes such as assessing the similarity of one event to another or the ease with which an example can be brought to mind, rather than reasoning with probabilities" (O'Hare, 2003, p. 204). While heuristics may shorten the time required to make a decision, it should be cautioned that these tools sometimes result in the wrong decision being made. The researchers concluded that heuristic mental shortcuts might have biased the pilots into making the incorrect decision; complacency could have also played a role in the incorrect decision. In another example, a pilot who is familiar with what a warning light indicates may, upon seeing it, be prompted to take corrective action without considering all possibilities the light may indicate. Typically, this works in favor of the decision maker because the decision making process is shortened. This can become an issue, however, when the decision maker lacks the knowledge or experience to 
recognize the heuristic or if the heuristic does not apply in that situation. Wickens (2002) and Casner (2010) highlight the importance of alerts and alarms being correct. If alerts and alarms frequently sound erroneously, the flight crew will soon become somewhat immune to the warnings. In a situation where a true warning or issue is present, the crew may then be slow to respond.

Bias can also impact pilot decision making. Decision bias is defined as ways in which pilots may ignore or omit certain components of the decision making strategy that prevents them from arriving at the best decision (Vidulich et al., 2010). Heuristics and bias may work together to delude the decision maker (or perhaps more appropriately allow the decision maker to delude himself or herself). Anchoring heuristics and confirmation bias are closely related. An anchoring heuristic is the idea that the information received first will be believed despite newer information that becomes available (Tversky \& Kahneman, 1974). The confirmation bias substantiates this when the decision maker then seeks information to confirm the anchoring heuristic (Einhorn \& Hogarth, 1978). An example is a VFR pilot's decision to continue into deteriorating weather conditions. The original weather report may have reported clear weather so that information is stuck in the decision maker's mind. Despite weather conditions worsening during the flight, the decision maker gathers information to encourage the continuation of the flight. Orasanu (2010) and Casner (2010) term this type of experience as plan continuation error (PCE).

Framing bias occurs when the pilot is faced with two negative or unpleasant decisions: a "sure loss" and a "risky loss" (Kahneman \& Tversky, 1984; Vidulich et al., 2010). For example, when faced with two negative choices, a person may be more likely to select the riskier choice instead of the sure loss, such as continuing flight into deteriorating weather conditions instead of turning around. This concept is extremely applicable toward the decision of using an airframe parachute or any other irreversible decision in aviation. Framing bias could encourage the pilot to continue pressing the situation, thereby choosing the "risky loss" (not deploying) instead of the "sure loss" (deploying), which may in fact be the safer choice (Vidulich et al., 2010). Awareness of this bias could assist pilots in reducing its impact on decision error.

Prospect theory is the idea that pilots will be risk averse when they can gain from the decision and risk takers when there is an apparent loss from the decision (Kahneman \& Tversky, 1979). Framing bias is very similar to sunk cost bias (Vidulich et al., 2010) and related to prospect theory. In sunk cost bias, pilots who have invested a lot into the flight (for example, money, time, and distance) will be more likely to continue. Again this could have a significant impact on the decision to choose an irreversible option. If the aircraft would be destroyed by deploying the aircraft's parachute system, it would be a significant financial loss for the pilot. According to sunk cost bias and prospect theory, the pilot may be more inclined to select the riskier option. Orasanu (2010) highlights some other issues that can result in erroneous decisions such as omissions, lack of knowledge, social factors, and personal stress.

Of particular interest in the current study was an examination of if and how decision-making biases would influence the deployment decision of an airframe parachute. These biases may be influenced by the type or training and opinions that surround the decision of how and when to deploy this safety device.

\section{Research Questions}

The current study sought to determine how pilots made the decision to deploy an airframe parachute system when encountering an emergency situation. Data were collected to answer the following research questions:

1. How do pilots recognize or know when to make the decision to deploy an airframe parachute?

2. What is the accuracy of pilot procedures when utilizing an airframe parachute?

\section{Methodology and Research Framework}

The current study completed a qualitative analysis of pilot decision making to a scripted flight scenario. The data were collected to provide insight into how pilots responded to the emergency situation. These qualitative data were analyzed to determine how educational components might have influenced the decision-making process. The study sought to gain an understanding of the training that participants received on when to use the airframe parachute. Participants were asked if they felt they received adequate training along with open-ended questions to determine if they could properly identify conditions where a parachute deployment was the most appropriate scenario.

A qualitative analysis was completed to examine participant survey responses after completing a scripted flight scenario. A survey instrument administered to participants gathered valuable insight into the actions and reactions of pilots when faced with this scenario. Qualitative data analysis revealed interesting findings as participants explained their course of actions during the scenario.

\section{Participants}

The target population for the study was flight students and part-time flight instructors in the subject university's Professional Flight Program. Students in the program currently complete flight training in Cirrus aircraft, which are equipped with an airframe parachute system. A convenience sampling of participants, with at least a 
private pilot certificate and an instrument rating, were selected to participate in the study.

Twenty-one participants completed the study, and data reflecting participant background were collected as part of the study. Information concerning age, total flight hours, total Cirrus aircraft flight hours, and total flight training device hours were obtained and a summary of these data are provided in Table 1 located in the Results section.

Information on pilot certificates and ratings was also collected. All participants held a commercial pilot certificate. Ten participants were certified flight instructors (CFI) and one participant held certification to teach in instrument conditions (CFII).

\section{Instruments}

The instruments used in this study consisted of an Advanced Aircraft Training Device (AATD) that replicated a Cirrus SR20 aircraft, a scripted flight scenario, and an electronic survey.

The AATD is a fixed-based, flight-training device that accurately replicates a Cirrus SR20 aircraft. The device consists of an aircraft cockpit with full aircraft instrumentation. A $170^{\circ}$ visual display wraps around the outside of the AATD. Behind the aircraft cockpit is an instructor station. The instructor station provides control of a number of aircraft parameters, weather, and aircraft failures. Photographs of the instructor station and cockpit are shown in Figure 1.

A script was completed for the experiment to ensure each participant would receive identical conditions during the simulated flight. The scenario was a flight from the Lafayette (KLAF) airport to the Quad Cities (KMLI) airport. The suggested cruise altitude was 4,000 ft. MSL. The weather for the scenario was instrument conditions with visibility set at 2 miles and cloud ceilings at 400 feet above ground level (AGL). The flight scenario and script were validated by an expert panel that consisted of designated pilot examiners from the subject university and training managers and supervisors from the aircraft manufacturer's training and standards department. The expert panel determined unanimously that the most appropriate outcome to the scenario was an airframe parachute deployment. Prior to beginning the scenario, study participants received a pre-flight planning packet. This packet included a standard weather briefing, en-route and approach charts, and a completed flight plan form.

Table 1

Summary of participant demographic information.

\begin{tabular}{lcrcrc}
\hline & N & Mean & Std. Dev. & Min. & Max. \\
\hline Age & 21 & 20.95 & 1.161 & 20 & 25 \\
Total Hours & 21 & 323.06 & 153.37 & 211.00 & 750.40 \\
Cirrus Hours & 21 & 204.95 & 96.38 & 51.80 & 478.00 \\
FTD Hours & 21 & 58.00 & 18.12 & 5.20 & 100.00 \\
\hline
\end{tabular}

Participants received approximately 15 minutes to familiarize themselves with the materials, and participants were only allowed to use supplies provided by the researchers. Participants began the scenario located on the parking ramp.

The survey instrument was developed by the researchers to gather qualitative data on participant experience during the scenario. The survey sought information on how well participants felt they had been trained on the airframe parachute system, reactions to their performance during the scenario, and to explain their decision on whether or not they utilized the airframe parachute system. A Cronbach's alpha analysis of the survey instrument indicated a strong reliability coefficient with a reported alpha level of 0.78 (Field, 2009). This value indicates that participants provided similar answers to similar survey questions and were consistent in their answering of the survey. The survey was administered electronically approximately two weeks after the flight scenario, and all participants who completed the flight scenario also completed the electronic survey.

\section{Procedure}

Participants for the study were solicited via e-mail and classroom announcements at the subject university. In order to participate in the study, a minimum of a private pilot certificate with instrument rating was required. Participants were scheduled to complete the simulator scenario, which took approximately 30 minutes to complete. Simulator scenarios sessions were scheduled and all sessions were completed over a 5-day period. When participants arrived, a research assistant provided the flight-briefing packet and participants were given approximately fifteen minutes to review the pre-flight information. Participants were then escorted into the AATD where the flight scenario began. Participants were instructed to complete the flight and respond to all situations as they would in a real aircraft. The researcher solely acted as a simulator operator and air traffic control, which was read directly from the flight script. The simulator sessions were video recorded for review during the data analysis process. After completion of the scenario, participants were excused, received $\$ 10$ USD compensation, and within two weeks e-mailed the post hoc electronic survey to reflect on their experience. Administering the survey two weeks after the scenario allowed participants time to reflect on their decisions.

\section{Results}

A summary of participant demographic is provided in Table 1.

Only nine out of the 21 participants deployed the parachute. This finding was not in agreement with the expert panel that validated the scenario and determined a parachute deployment to be the most appropriate scenario 

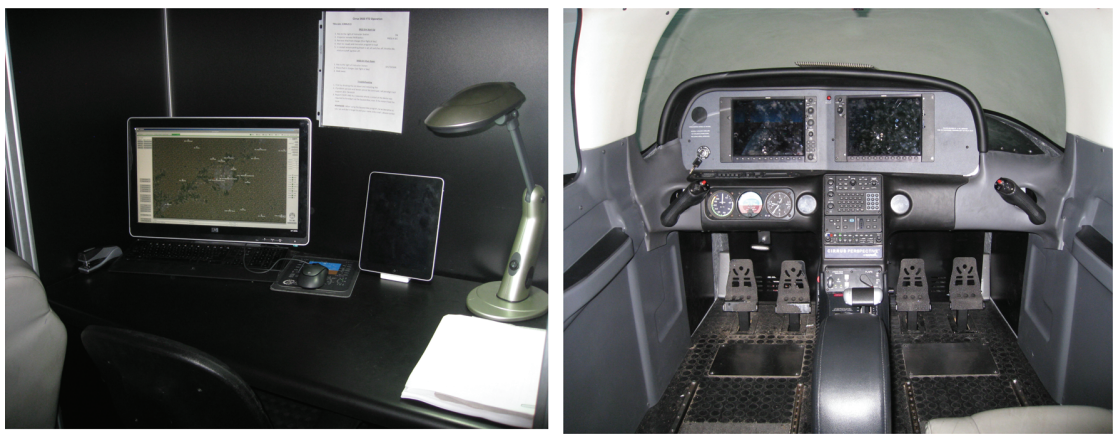

Figure 1. Instructor station (left) and the Cirrus SR20 AATD.

outcome. Of the nine participants that did deploy, only three followed the correct deployment procedure as outlined in the aircraft Pilot's Operating Handbook $(\mathrm{POH})$. A survey was used to determine why or why not participants decided to use the airframe parachute system, and all 21 participants completed the survey. Participants were asked their agreement or disagreement with the statement that if they were to fly the scenario again, they would react the same way. The majority of students, $52 \%$ agreed or strongly agreed with this statement; however, $38 \%$ disagreed, and $10 \%$ neither agreed nor disagreed.

The participants who deployed the parachute were asked an open-ended question to explain their decision; nine participants responded to this question. Three participants identified that they were trained to deploy the parachute if the engine failed in instrument meteorological conditions. Participants referenced the low ceiling of the clouds and the inability to glide to the nearest airport. Some identified a "decision altitude" that if they descended to and were unable to restart the engine or be in visual conditions, they deployed the parachute. These views tended to be in agreement with scenarios the expert panel determined to be appropriate parachute deployment situations.

Participants who did not deploy the parachute were asked to explain why that decision was made; 12 participants responded to this question. Answers as to why the parachute was not deployed tended to fall in one of four groupings.

\section{Category 1: Deployment Did Not Apply to Scenario}

Two participants said that a parachute deployment did not apply in this situation. One participant said: "there are defined situations when to use the CAPS and this was not one of them." This response was contradictory to statements made by participants from the group that did deploy and cited their reasoning as being standard operating procedure at the subject university. An obvious concern related to this response from participants was the lack of recognition of CAPS usage. The expert panel members indicated that CAPS was the appropriate outcome in this scenario; therefore, it is interesting that a few participants did not feel this was an appropriate time to use the airframe parachute.

\section{Category 2: Concern for Aircraft Damage}

A second concern expressed by participants who did not deploy the parachute was the risk of damage to the aircraft. Three individuals expressed this concern. These participants determined it was more beneficial to complete a forced landing because they felt that less damage would occur to the aircraft. However, one participant who stated this also recognized the increased risk: "although it was risky not to deploy [the parachute] with a sure thing I felt it was still a good decision to continue a forced landing." The concern for damage was also closely linked with the concern of aircraft control. Participants stated that they felt they would be able to land the aircraft in a field and cause less damage to the aircraft than if they had used the parachute system. An interesting view from these participants was the great concern for aircraft damage. While it is possible that if a forced landing was successful, there may be less damage to the aircraft than if the parachute was deployed, there is also greater risk from a forced landing that impact forces could be more harmful to the aircraft's occupants.

\section{Category 3: Desire for Aircraft Control or Delayed Decision Too Long}

Four participants expressed the decision to continue with a forced landing instead of using the parachute because it would allow them control of the aircraft all the way to the ground. "I was in a flat area where I could control myself to a safe landing" said one respondent. Some participants felt that they had waited too long to consider the parachute or they were too low to have adequate time to utilize it. Two interesting points raised by participants are controlling the aircraft and waiting too long to decide to use CAPS. Since many aircraft do not have an airframe parachute, pilots have no option except to complete a glide to a forced landing. Having an airframe parachute on-board may change the mentality of flying the aircraft. It is possible that participants are expressing a lack of wanting to resign to using the parachute and instead feel more in control by maintaining a glide to a forced landing. Additionally, if participants wait too long to decide to deploy the parachute, 
there may not be enough altitude remaining to then deploy it. This highlights the balance in assessing the situation, making the necessary decision, and committing to either a forced landing or parachute deployment.

\section{Category 4: Forgot or Did Not Feel Trained}

A final area that was noted by three participants was that they either forgot or had not been trained on when to use the parachute. "While I have flown (subject university) SR20s in real life and have some time in the AATD, I have never received any formal training in the SR-20 AATD and have never used the CAPS simulator in an appropriate scenario," explained one respondent. Other participants felt like they thought of it too late in the emergency and had lost too much altitude to deploy the parachute safely. This response is perhaps the most concerning. Adding any safety feature to an aircraft is only valuable if operators are willing to use it. Having a parachute system installed but forgetting about it would be similar to having seatbelts installed, but forgetting to fasten them before flight.

\section{Participant Views of Deployment Scenarios}

All participants were asked to describe the conditions under which they would consider deploying the airframe parachute in an open-ended question. Participants were able to identify multiple situations in which they felt a parachute deployment would be the most appropriate decision. Since the question was administered as an internet-based survey, it is unclear if participants responded to this question from memory or if external sources were used to provide assistance in identifying likely parachute deployment scenarios. When participants were asked if they felt they had received adequate training on when to and when not to use the parachute, $24 \%$ disagreed, and $71 \%$ either agreed or strongly agreed with this statement. One respondent neither agreed nor disagreed with that statement.

\section{Discussion of Findings}

Study findings may be the result of, or influenced by, framing bias (Kahneman \& Tversky, 1984). Framing bias occurs when a pilot has to choose between a "sure loss" and a "risky loss." When making an irreversible decision, such as to deploy an airframe parachute, the aircraft will likely be a sure loss. Framing bias could influence participants to make the riskier decision (in this study's scenario) of gliding down to a forced landing even without much distance between the ground and cloud ceiling (400 feet), instead of choosing the parachute deployment, which would be a sure loss situation but safer. Supporting statements of this analysis are found from participants in Categories 2 and 3 of the results section. If participants are not aware of this bias, it could subconsciously delay or prevent taking the correct action. For reasons such as these, Casner (2010) and Dismukes (2010) both advocate for the enhancement of pilot education on decision making and decision-making biases. The goal of this type of education would be to teach pilots how bias influences their decisions and assist them in recognizing and reducing the negative impact of biases. Additionally, guidelines and policies may assist pilots in responding appropriately to situations, thereby reducing the effect of framing bias.

Training may also play a role in assisting those participants from Category 4 who forgot about using the parachute. Study participants highlighted the need for making a decision or for waiting too long to make the deployment decision. It is possible that greater knowledge, training, and standardization may help participants establish clearer guidelines on when to use the CAPS system and more information to make the most appropriate decision.

It appears that the results of the study were also inconsistent across the sample. Some participants seemed to have a clear understanding of parachute usage scenarios while others were less clear. The inconsistency of participant responses may suggest the need for a more formalized training program to ensure consistency in both awareness and understanding of when and how to use a safety feature such as an airframe parachute system. Despite the subject university operating the aircraft for approximately three years at the time of the study, it may be inaccurate to assume that all members of the population have adapted to having an airframe parachute installed in the aircraft.

\section{Conclusions, Limitations, and Recommendations}

The purpose of this study was to complete a qualitative analysis of the decision-making process used by pilots to determine whether or not to deploy an airframe parachute system. A limitation to the present study was the small sample size, which limits the generalizability of these findings, along with all participants only being from one university. Additional research should be completed to verify the accuracy of these findings and determine if the inconsistency in deployment scenarios exists across other populations. A larger scale survey of participants may provide greater insight into understanding pilot decision making as it relates to a parachute deployment along with verifying the findings of the present study.

A finding of concern was the discrepancy between participants' response to the engine failure and the opinion of the expert panel as to the most appropriate outcome: a deployment of the airframe parachute system. Additionally, only $33 \%$ of participants who did use the parachute system followed the correct procedure for its deployment. Further research is necessary to investigate the causal factors of this discrepancy between experts and participants. While the university has had aircraft with parachute systems for 
approximately three years, perhaps awareness and education on how and when to make the decision to use this device have been inconsistent. It may be a false assumption that just because a new piece of equipment is being utilized, those operating it will automatically gain awareness on when and how to use all safety features.

\section{References}

Beach, L. R., Lipshitz, R. (1993). Why classical decision theory is an inappropriate standard for evaluating and aiding most human decision making. In Klein, G. A., Oranansu, J., Calderwood, R., \& Zsambok, C. E. (Eds.), Decision making in action: Models and methods (pp. 2135). Norwood, NJ: Ablex.

Bond, S., \& Cooper, S. (2006). Modelling emergency decisions: Recognition-primed decision making. The literature in relation to an opthalmic critical incident. Journal of Critical Nursing, 15, 10231032. http://dx.doi.org/10.1111/j.1365-2702.2006.01399.x

Casner, S. M. (2010). General aviation. In E. Salas, \& D. Maurino (Eds.), Human factors in aviation (pp. 595-628). San Diego, CA: Elsevier. http://dx.doi.org/10.1016/B978-0-12-374518-7.00019-5

Craig, P. A. (2000). Pilot in command. New York: McGraw-Hill.

Dismukes, R. K. (2010). Understanding and analyzing human error in realworld operations. In E. Salas, \& D. Maurino (Eds.), Human Factors in Aviation (pp. 335-374). San Diego, CA: Elsevier. http://dx.doi.org/10. 1016/B978-0-12-374518-7.00011-0

Einhorn, H. J., \& Hogarth, R. M. (1978). Confidence in judgment: Persistence of the illusion of validity. Psychological Review, 85, 395 416. http://dx.doi.org/10.1037/0033-295X.85.5.395

Field, A. (2009). Discovering statistics using SPSS. London: Sage.
Hitchcock, L., Bourgeois-Bougrine, S., \& Cabon, P. (2010). Pilot performance. In J. A. Wise, V. D. Hopkin, \& D. J. Garland, Handbook of aviation human factors (pp. 14/1-14/19). Boca Raton: CRC Press.

Kahneman, D., \& Tversky, A. (1979). Prospect theory: An analysis of decision under risk. Econometrica, 47(2), 263-291. http://dx.doi.org/ $10.2307 / 1914185$

Kahneman, D., \& Tversky, A. (1984). Choices, values, and frames. American Psychologist, 39, 341-350. http://dx.doi.org/10.1037/0003066X.39.4.341

Klein, G. (2008). Naturalistic decision making. Human Factors, 50(3), 456-460. http://dx.doi.org/10.1518/001872008X288385

Klein, G. A., Orasanu, J. Calderwood, \& Zsambok, C. E. (1993). Decision making in action: Models and methods. Norwood, NJ: Ablex.

Lipshitz, R., Klein, G., Orasanu, J., \& Salas, E. (2001). Focus article: Taking stock of naturalistic decision making. Journal of Behavioral Decision Making, 14, 331-352. http://dx.doi.org/10.1002/bdm.381

O'Hare, D. (2003). Aeronautical decision making: Metaphors, models, and methods. In P. S. Tsang, \& M. A. Vidulich (Eds.), Principles and practice of aviation psychology (pp. 201-237). Mahwah, NJ: Lawrence Erlbaum.

Orasanu, J. M. (2010). Flight crew decision-making. In B. Kanki, R. Helmreich, \& J. Anca (Eds.), Crew resource management (pp. 147-179). San Diego, CA: Elsevier. http://dx.doi.org/10.1016/B978-0-12-374946-8. 10005-6

Tversky, A., \& Kahneman, D. (1974). Judgment under uncertainty: Heuristics and biases. Science, 185, 1124-1131. http://dx.doi.org/10. 1126/science.185.4157.1124

Vidulich, M. A., Wickens, C. D., Tsang, P. S., \& Flach, J. M. (2010). Information processing in aviation. In E. Salas, \& D. Maurino (Eds.), Human factors in aviation (pp. 175-215). San Diego, CA: Elsevier. http://dx.doi.org/10.1016/B978-0-12-374518-7.00007-9

Wickens, T. D. (2002). Elementary signal detection theory. New York: Oxford University Press. 